\title{
La crónica de Ventura García Calderón
}

\author{
Esther Espinoza E. \\ Universidad Nacional Mayor de San Marcos
}

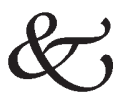

Resumen

Este estudio brinda una lectura del libro de crónicas Bajo el clamor de las sirenas de Ventura García Calderón, en el que ofrece su visión de la barbarie instalada en el centro de la civilización, mediante la guerra. La mirada del autor logra extraer de esa experiencia la oportunidad para universalizar los valores franceses, capaces de convocar a todos los pueblos y culturas, en una nueva era de avance tecnológico.

Palabras claves: Crónicas, primera Guerra Mundial, Ventura García Calderón, frivolidad, modernidad, crisis.

\begin{abstract}
This article studies the book of chronicles Bajo el clamor de las sirenas of Ventura García Calderón, which offers his vision of barbarism installed in the center of civilization, through war. The look of the author manages todraw from that experience the opportunity to universalize the French values, able to summon all the peoplesand cultures in a new era of technological advancement.
\end{abstract}

Key words: Choronicles, First War, Ventura García Calderón, Frivolity, Modernity, Crisis.

\section{Introducción}

El estudio de las crónicas de Ventura García Calderón obedece, en primer lugar, a un interés en el género que ha sido motivo de mis últimas investigaciones en relación al horizonte de la crónica en el Perú, desde Enrique Carrillo hasta Vallejo. Esta investigación quiere sumarse a la labor de reivindicación que en recientes estudios, en especial dentro de la Universidad de San Marcos, se viene realizando en torno a la figura de Ventura García Calderón y que, en definitiva, va a terminar revisando toda la crítica referida a la obra de este 
escritor. Es posible pensar en una lectura anacrónica como base de la confusión, de lectura sesgada, de relegación por razones ideológicas o por el uso de categorías externas al fenómeno literario que es ante todo un fenómeno de lenguaje. Como quiera que esa crítica se ha producido en torno a su obra narrativa, no la vamos a abordar aquí. El caso es que, como suele suceder con los escritores modernistas, su tendencia es difícil de definir, su eclecticismo confunde y por si fuera poco, sus crónicas se integran tardíamente al estudio de su obra literaria. Linda Egan analiza la obra cronística de Monsiváis partiendo de lo señalado insistentemente por este autor: la crónica es literaria porque su lenguaje es estético.

La idea de la literatura como ficción es una idea del siglo XIX y ha perjudicado el estudio de las crónicas dentro del espectro de la literatura, en especial en Latinoamérica. Los últimos estudios sobre la literatura de la no ficción, abonan a favor de una integración de la obra cronística dentro de la obra literaria de los autores y extienden su interés hacia la autobiografía, los diarios etc.

José Martí, Enrique Gómez Carrillo, Valdelomar o Vallejo, como VGC, son autores que viven en una etapa crucial en la historia de Occidente. Es la época en que el optimismo por la modernidad es cuestionado por la brutalidad de la guerra, es la época del nacimiento de un nuevo arte a la luz del conocimiento científico y de las nuevas tecnologías, también es el tiempo de las masas que exigen protagonismo en la escena política y cultural. Pero también es la época de búsqueda de modelos, del superhombre que habría de continuar y dirigir la siguiente etapa civilizadora. Francisco García Calderón, hermano de nuestro escritor, habría de hacerlo en sus ensayos pero proyectando salidas a partir de su análisis de la realidad peruana y latinoamericana. Él también fue un referente para los latinoamericanos afincados en París y en opinión de nuestro recordado filósofo sanmarquino, Juan Abugattás, "la agenda del debate social y político de la primera mitad del siglo XX, en nuestro país, fue puesta fundamentalmente por dos personas: Gonzáles Prada y Francisco García Calderón" (168: 2005). Esta situación de crisis en la que escriben VGC y los otros autores referidos, le confiera actualidad a las crónicas de Bajo el clamor de las sirenas, después de todo, la modernidad se expresa en esa constante crisis. El lenguaje estetizado de la crónica modernista de VGC, las referencias clásicas, el interés por el lenguaje popular, la erudición, el análisis de la prensa y del escenario en el que cree ver la definición del destino del mundo, hacen de esta serie una muestra muy interesante de su lectura de los tiempos modernos.

La primera hipótesis que guía nuestro análisis es que las crónicas de Bajo el clamor de las sirenas, revitalizan el tema de la civilización y la barbarie, solo que en este caso la barbarie es interna, se halla instalada en el centro de la civilización y es producida por ella misma. Se trata ahora de una barbarie tec- 
nológica o sustentada sobre la base del avance armamentista que entusiasma a los ingenieros. Es la misma eficiencia y modernidad que ve Valdelomar en la Escuela Militar de Chorrillos en 1910 y que juzgara con entusiasmo como signo de recuperación de un país como el Perú que, precisamente, había sido sometido por su inoperancia tecnológica, además de otras razones. VGC no asocia los cañones con el legado francés, atribuye a Francia un poder basado en razones inmateriales que no se pueden medir por peso. Sin embargo, ante el avance alemán señala: "La cordura, la suprema razón, necesitan como Minerva, casco y lanza” (1986: 165).

Una segunda hipótesis es que la estrategia discursiva, regida por un hablante "frívolo", busca enfatizar la forma de entender el mundo desde la perspectiva francesa, capaz de unir en una misma experiencia la elegancia y la muerte, la dignidad y el sufrimiento, todo esto "sin perder la sonrisa", aunque esta misma sonrisa sea una máscara. La frivolidad es una estrategia ideológica para enfrentar la guerra, con la convicción de que el mundo habrá de rendirse ante Francia o mejor dicho, ante los valores universales que propone Francia para el futuro.

En ese sentido, como corolario de la idea anterior, el hablante se expresa mediante un nosotros insistente y coherente, a pesar de que hace mención a su infancia en el Perú. Asume la identidad francesa que es como asumir la identidad del mundo. Su nosotros tiene la fuerza del soldado que defiende en la escritura al país que está siendo cercado, en terrenos ideológicos por enemigos a los que es preciso neutralizar. Se trata de crónicas en pie de guerra, escritas por un escritor peruano (conocido como tal en el medio a pesar de haber nacido en Francia) que asume la identidad universalista francesa.

\section{La mejor arma es la frivolidad}

En el comentario que Enrique Gómez Carrillo hace al primer libro de crónicas de Ventura García Calderón titulado Frívolamente (París, Garnier,1908) compara el arte de la muerte que practican los japoneses con el gesto del frívolo. "Yo sé que voy a morir y en el fondo padezco, pero este mi dolor no ha de convertirse en molestia para los demás” (1968:104). La máscara, es el arma del frívolo, con la cual puede enfrentar las situaciones más graves y los temas más profundos, sin inmutarse. Al igual que el dandy o precisamente porque practican el mismo arte, el frívolo no se inmuta, tanto si se trata de la muerte, de la guerra, de un asunto ligero o de un tema erudito. De modo que el sentido que adquiere el término se aleja de su acepción literal, se define más bien en relación con la práctica del cronista, el frívolo es alguien que hace en la crónica lo que el dandy hace en la vida, es decir, escribir sin perder la sonrisa, sobre los temas más graves. VGC, dice Gómez Carrillo, no quiere hacer "poesía durable", a pesar de que tiene arte para ello, y más bien prefiere hacer "prosa cronique- 
ra", considerada por su cotidianeidad como efímera; incluso confiesa: "Porque yo he nacido cronista, nada más que cronista” (1968:104). El autor, a diferencia de la mayoría de escritores que practicaron este género en la época, está orgulloso de su suerte literaria, ve en lo efímero la trascendencia que se atribuía a la poesía. Los tiempos han cambiado, para los cronistas latinoamericanos que se iniciaron en los periódicos a fines del siglo XIX, era impensable "nacer cronista”, la crónica, en los años de la Primera Guerra, ya se había asentado con comodidad en ese espacio intermedio entre el arte desinteresado del literato y la exigencia comercial del público. Pero, como anunciara en 1910 Enrique Carrillo "Cabotín", sus días estaban contados. El público, esa "turba melenuda" del poema "El Duque", de Eguren, habría de exigir pronto nuevos productos a los creativos periódicos.

Bajo el clamor de las sirenas, es una serie de 27 crónicas escritas entre 1914 y 1919, la mayoría de ellas en París y otras en Madrid u otros lugares de Europa y publicadas en La Nación de Buenos Aires, El Imparcial de Madrid, El Comercio de Lima. En ellas acomete, probablemente, uno de los temas más difíciles para un cronista "frívolo": hablar de París en guerra. La escritura cronística hace correr un riesgo extremo al escritor, la periodicidad de los escritos muestra el proceso mismo de la creación que se va gestando día a día, ante los ojos de los lectores que, a diferencia de nosotros que vemos la obra acabada, acudieron a la lectura fresca del momento para observar los recursos que el escritor exhibía frente a una realidad cada vez más compleja. ¿Cómo hablar de París, el centro simbólico de la civilización y de la modernidad, ahora en guerra? La fórmula del japonés que enfrenta la muerte con elegancia, es crucial para explicar la perspectiva de hablante, enfrentar las situaciones más graves de la experiencia humana, sin perder la sonrisa. La pose del escritor modernista, dandy y frívolo, se pone a prueba con la guerra, o mejor dicho, la guerra va hacer evidente que el hombre de las élites juega sus últimas cartas, "la frivolidad es nuestra mejor arma", dice VGC asumiendo el nosotros que su nacimiento parisino le otorgaba con legitimidad, y de este modo defiende la actitud del hombre moderno y elegante, afincado en Paris, la ciudad que creó la frivolidad y que ahora no debe renunciar a ella. Para VGC no resulta sorprendente que los franceses más conservadores, como Donnay (dramaturgo conservador francés), pregonen que ha llegado la hora de expiar el pecado de la liviandad y la ligereza parisiense, porque "padecen de una epidemia de moralismo". Pero para las mentes más preclaras, que él atribuye a los intelectuales de la Sorbona, la virtud y el vicio continuarán en la misma proporción después de la guerra. Precisamente ese afán moralista que encarna también una posición política, le permite desplegar sus convicciones acerca de la mentalidad parisiense. La frivolidad que se expresa principalmente en la crónica, como en la tragedia griega, concentra en la máscara de permanente sonrisa, la fuerza del dios Dionisos que rechaza 
los efluvios negativos provenientes del exterior, pero no expone la sangre en escena, ni busca la lástima del público, sino la compasión, que es condolerse y a la vez identificarse, sumarse a la defensa. Se trata de acción, no de depresión. Para VGC, la guerra ha expuesto los valores que deben forjar al ciudadano del mundo, identidad con Francia, que es al mismo tiempo una propuesta de pluralidad, de tolerancia, de convocatoria y de democracia parlamentaria.

Las crónicas van a ser necesariamente una defensa, con las armas de la retórica modernista, de un sistema político parlamentario (porque excluye y critica al colonialismo supérstite que es el origen del odio), de libertades democráticas y de costumbres cosmopolitas, que el mundo entero debe reconocer y aceptar como creados en Francia. La duda ofende, y los españoles que se mantuvieron aparentemente neutrales creen ver en la guerra del centro de Europa una expiación y una oportunidad, la estampida de los turistas atraería sus despilfarros hacia España y con ello la salida de la pobreza. Pero VGC se muestra escéptico e ironiza con el éxito que tendrán los pobres de la Puerta del Sol que piden "una perrilla para un panecillo" que esquilmarán a los millonarios, pero que serán exitosos cicerones en la era del turismo.

España había demostrado muy poca solidaridad ante la guerra. El conservadurismo, la religiosidad cerrada del pueblo español, su poca disimulada atracción por los modelos autoritarios, se expresó en la prensa. España es en cierto modo el país donde se ha detenido el tiempo, su mentalidad le impide aceptar el liderazgo francés e intervenir defendiendo sus valores.

Leyendo los periódicos se descubre no solo la admiración al fuerte sino un rencor muy hondo y motivado. La mitad de los diarios, por lo menos, comenta los éxitos de Francia con ironía, ve apuntar con avidez en cada horizonte galo, junto a la flecha del campanario, el casco de un hulano. Los periódicos que así tienen urgencia de ver sitiado a Paris se llaman El Correo Español, La Tribuna y tal vez $A B C(1986: 121)$.

Pero Francia tiene parte de culpa, "nuestra glotonería colonialista" dice, es el origen del rencor español y el odio alemán. Pero aun así París es la Babilonia podrida. Nadie reconoce ahora su larga historia de lucha por la libertad. VGC vincula la estrechez de la mirada española, con la religión y la situación económica, todo es parte de un mismo fenómeno.

Porque esta España desangrada por guerras, exhausta por piraterías de políticos, nutrida con gazpacho y con promesas, necesita sobre todo comercio y no política, concentración económica y no expansiones coloniales (1986:106).

Se trata del ideal liberal moderno expresado con claridad, que propone romper con el pasado. La guerra ha expuesto la verdadera careta de los conservadores.

La misma aversión que siente el mundo entero por Alemania imperialista y petulante, la sienten los reaccionarios del universo por el país volteriano que expulsara a los frailes (1986: 122). 
El análisis es profuso, pero siempre mediante imágenes, símiles y expresiones de un lenguaje que no abandona el arte. La retórica modernista recurre a los espacios predilectos, como China y Estambul, y a la importancia de las cosas fútiles como la moda o el corte de pelo, para demostrar que se ha iniciado una era universal basada en los moldes franceses o mejor dicho que ahora sí, no solo Europa, el mundo entero debe afrancesarse.

En China, apresuradamente, los libertarios van a casa del peluquero a ser occidentales en seguida, se despojan de la túnica de seda, revisten una levita mal cortada. ¿Y cómo comienzan la vida libre? No cantarán las viejas loas monorrítmicas a su Confucio negro, sino la Marsellesa en Chino, destrozada pero eficaz. Cuando proclaman la república española, le ponen en el acto el gorro frigio a la Virgen del Pilar, que siendo madre del igualitario de Galilea, era republicana fácilmente. (1986:122)

Para el anticlerical escritor, París no solo ha sido centro del mundo hasta entonces, sino que ahora, en la guerra contra el tirano alemán, se libra la guerra contra la tiranía universal. La nueva identidad planetaria, el afrancesamiento universal, se basa en el respeto de las libertades. Las repúblicas del mundo deben propender hacia las democracias, y los países de Europa deben entender que ha terminado la era de los imperios. El futuro se propone como una sumisa aceptación del centralismo francés, pero no en una fórmula que niegue las libertades políticas sino en un llano reconocimiento de que el mundo moderno ha sido creado por Francia

Acostumbrada a dirigir el mundo hace más de cien años, Francia no puede callar su legítimo orgullo. El mundo está recibiendo de Paris el último corte de faldas y el dernier cri del estilo o del pensamiento. Los sombreros, la literatura, las costumbres, los vicios, toman el molde de la gran ciudad. El adulterio parece inventado allí, no porque no existiera desde la Biblia, sino porque los únicos novelistas que leemos y lo describen son franceses (1986:123).

La máquina francesa de la ideología ha cubierto todos los campos y no hay porqué mirar a otras tradiciones si existe una tan completa, el trabajo ya está hecho, la adhesión es lo que queda. En su hiperbólica defensa VGC deja en claro ante los moralistas y los conservadores, que la guerra habrá de fortalecer el legado de Francia porque es la manera de engancharse con otras herencias europeas, que hasta entonces han sido cribadas por el tamiz francés, que las ha difundido y defendido.

Las ideas son peligrosas, repite con Nietzsche, pero sería tal vez mejor que la profesión de pensar esté reservada a solo "unos cuantos sabios prudentes". Esta guerra ha hecho que sus convicciones sobre la capacidad de pensar y de crear ideología se confirmen, teme a las multitudes porque no las conoce ni comprende y las asocia, como todo intelectual de la época con desorden y vulgaridad. El odio a Francia podría basarse también en el engreimiento del fran- 
cés plebeyo "para quien todo forastero es bárbaro, su ignorancia agresiva de la vida extranjera, su silueta elegante, su fatuidad, sus barbas sucias” (1986: 124).

\section{Nosotros los franceses...}

VGC nació en París en 1886, pero se instaló allí después de pasar su infancia en el Perú, en 1906, luego de la muerte de su padre. Junto con su hermano Francisco fueron miembros de una generación de escritores latinoamericanos, pero fueron vistos como el núcleo de esa generación. Al decir de LAS, "es el más francés de los peruanos y también el más tercamente peruano de cuantos nacieron en París". En reciente estudio, Jorge Valenzuela Garcés, verifica contundentemente el prestigio que tuviera su obra y su figura de intelectual, propuesto además para el Premio Nobel de Literatura en 1933 por un grupo de destacadísimos intelectuales.

Para el momento en que escribe las crónicas, la voz plural que asume VGC no es la de un extranjero recién llegado. Todo lo contrario, nuestro autor se ha asentado en el mundo cultural francés, de modo que todo aquel que llegara a París, se vinculaba con él, como bien lo testimonian Vallejo o Valdelomar en sus crónicas y como sucedió con Alfonso Reyes que viene huyendo del México de Madero en 1913. Este autor, dice de VGC, de acuerdo a la cita de Luis Loayza:

"Es un perfecto parisiense (...). Conoce todos los teatros y espectáculos, trata a todo el mundo, sobre todo está al tanto de cada sala de té que se inaugura. Es el primer hombre que conozco que hablando con señoras, con visitas, las divierta sin dejar de ser literato y sepa mezclar admirablemente el tema literario que se agita en el fondo de todas sus conversaciones con los atractivos visuales y objetivos de la vida real y actual. Rarísimo don, para mí al menos del todo vedado. Tiene una alegría intelectual tan constante que se siente uno, que me sentí yo -pobre representante de un pueblo triste, pobre analista sin fe más que en el procedimiento y nunca en las finalidades- muy inferior a él" (1990: 120).

La superioridad del que se siente triste, enfermo de pobreza, contrasta con la vitalidad intelectual, la alegría del peruano que incluso es didáctico con las damas, que significaba saber llegar a las mentes más simples, lo cual era parte de su espíritu democrático, como si sus conocimientos no tuvieran que ser exclusivos para mentes dotadas.

En su ensayo autobiográfico Nosotros, VGC recuerda su adolescencia y refiere lo común de un muchacho en el Perú, pero al hacerlo responde desde el latinoamericano que es y en ello unifica la experiencia. “¿Cómo era un adolescente peruano y podríamos decir hispanoamericano en los comienzo del siglo XX? (1986: 519). Aquí explica lo que sería el origen de la capacidad de comprender distintas situaciones humanas, lenguas y culturas. En Lima la inestabilidad política, homolagada en cierta forma con la inclemencia de los temblores 
y terremotos, instalados en la memoria familiar debido a que su madre había sobrevivido al terremoto de Arica de 1868; las lecturas del colegio francés estancadas en el romanticismo decimonónico, era necesario leer a Renán y a Voltaire para menoscabar la autoridad de sus maestros católicos. Pero la multa vieja le cuenta cuentos de aparecidos y de fantasmas y de una muchacha llamada Blancaflor, infanta desobediente que ha huido de España y es perseguida por su cruel padre hasta estas tierras. Durante la guerra civil tuvo que pasar días de encierro y angustia, las balas atravesaban las blandas paredes de quincha, los incendios en la ciudad campeaban y las torres de las iglesias eran tomadas como torreones para bombardear otras iglesias. Finalmente dice refiriéndose a sí mismo: "Este niño no irá al colegio en ocho días, pero ha aprendido en una semana mucho más que en varios años de Humanidades" (1986: 522). Y haciendo un distingo se conduele de los francesitos de la preguerra que no sabían de balas y obuses porque no habían pasado su infancia en el Perú.

En sus crónicas de Bajo el clamor de las sirenas utiliza siempre el nosotros y es sobre este pronombre que se sostiene la identidad que proponen los textos. Innegablemente vinculado al Perú, por su obra y su nacimiento, su terca identificación con París ni es excluyente ni anula sus orígenes. París le ha permitido aflorar un sentimiento que se instala debido a la inminente destrucción por la guerra y que no hace sino alertar sus defensas sicológicas aprendidas en el Perú. El proceso de asimilación de la identidad no se detiene y más bien se ha ampliado con la guerra a los otros no europeos.
"Negros inmensos, formidables, con un vellón enredado por cabello y el más agresivo continente, pero con extraña dulzura en los ojos, de felpa (...). No le tienen miedo al frío, al combate perpetuo, a la metralla, sino a las botas. Cuando les ordenan avanzar, su primer acto es descalzarse y tirarlas" (1986: 149).

La escena se reconstruye porque es importante comprender la procedencia de estos soldados, el otro mundo de donde vienen, donde no se usan zapatos, no es civilizado, pero sus hijos son valientes. Su valentía y sus acciones han merecido una medalla, pero en el momento mismo de la premiación saben que serán castigados por indisciplina y entonces acuden a una artimaña, a una picardía algo patética: robar las botas de un enemigo y jurar que son suyas. Su valentía es indómita, casi no pueden comprender las normas de la guerra, pero tampoco se comprende su rechazo a usar zapatos, para la entrega de la medalla o para luchar en la guerra, ambos grupos franceses o africanos, tendrán que renunciar a parte de su conducta cultural, aunque finalmente las botas sean ajenas.

"Y no comprenden que se trate a los alemanes con tanto mimo. A este admirable negro circundado de amuletos, porque es hijo de marabú, fue preciso detenerlo a viva fuerza, una noche. Avanzaba en la sombra hacia el lecho de un alemán, esponjado y felino, como en los ataques de su tierra bravía, con el cuchillo que no abandona entre los dientes" (1968: 150). 
La imaginación de nuestro escritor se sobresalta ante el representante de esta raza tan vital, que finalmente se incorpora, con su religión y incluso, al "mundo civilizado" de la guerra europea y con ello a ese "nosotros" que invoca en sus crónicas. Las fórmulas de la identificación son equívocas desde el origen, pero generan estrategias más básicas de agrupamiento humano. "París es para ellos como una sucursal de la Meca y el Kaiser algún profeta disidente” (1968: 150).

La guerra no ha hecho sino sacar a flote al salvaje que llevamos dentro.

"Y si les habláis a los convalecientes casi indemnes de regresar al combate, se entusiasman. No es solamente el deseo de concluir con el invasor. Es otra cosa. Recuerdo que un amigo que habitara largos años en la selva amazónica, se aburría en su delicioso home de Leicester Square" (1968: 151).

Resulta interesante cómo este peruano-francés evoca la vida de las tierras amazónicas como espacio donde "se tiempla el alma", quien ha probado esa vida, como en la tierra bravía del África, "desdeña casi las felicidades familiares de nuestra vida burguesamente muelle". La guerra parece haber sido el factor de acercamiento de estas realidades, la africana, la amazónica, la de la infancia en Lima en la guerra civil y ahora la francesa.

\section{El futuro}

Dos ideas amenazan, para nuestro escritor, el futuro de Francia después de la guerra. La idea la sostienen las mentes más conservadoras, una nueva moral en la que las mujeres pierdan su gracia y su sonrisa, su veleidad y su forma de disfrutar la vida. Pero tal argumento tiene una contradicción que los conservadores no ven, las mismas muchachas veleidosas que flirteaban con los turistas en París, son ahora enfermeras delicadas y maternales. Teme también que se sancione la frivolidad. En la última crónica "Le jour de glorie et arrivé", del 14 de julio de 1919, resalta la espectacularidad y el protagonismo de la multitud. En las trincheras no solo se había creado una nueva Francia sino también un nuevo lenguaje, afirma. Invoca la presencia de Rubén Darío que habría cantado la victoria inigualablemente, observa la necesidad de "aliarse" con la Quinta Avenida y celebra a la Francia de pie, con sus veinte razas de fiesta.

\section{Conclusiones}

Bajo el clamor de las sirenas, siendo un texto que habla de otro espacio, debe estar incorporado a la reflexión sobre la literatura peruana porque se trata de un peruano que habla desde "el centro del mundo" a los latinoamericanos, para que se identifiquen con la causa francesa. 
El texto propone una utopía universalista, donde los pueblos del mundo se identifican bajo una misma identidad civilizadora de corte francés, pero proyectada hacia la modernidad. Este hecho no deja de ser una conquista provocada por la guerra.

La estrategia del hablante que usa la máscara de la frivolidad, como la de los coreutas del coro griego, constituye una postura ideológica que se asume como coraza ante la orfandad de la guerra, pero que constituye la fuerza de una mentalidad moderna que no se asocia con la moralidad hipócrita del catolicismo, representado en el pueblo español, sumiso ante el autoritarismo y anclado en el pasado.

Una vez más este estudio, entre los recientes referidos a la obra de Ventura García Calderón, confirma la importancia de su obra dentro de la construcción de la tradición literaria en el Perú, aportando precisamente una visión moderna, plural, universal y tolerante, en plena crisis del "antiguo régimen" . Resulta de gran importancia su visión abierta hacia el futuro que trata de explicar.

\section{Referencias bibliográficas}

ABUGATTÁS, Juan. (2005) La búsqueda de una alternativa civilizatoria. Lima: Ministerio de Educación.

CORNEJO POLAR, Antonio (1989) La formación de la tradición literaria en el Perú. Lima: CEP

DELGADO, Luis Humberto (1949) Diálogos con Ventura García Calderón. Lima: Imprenta Torres Aguirre.

ESPINOZA, ESPINOZA Esther (2002) "La crónica modernista y su realización en Viendo pasar las cosas" en Letras 103-104; pp.263-272

ESPINOZA, ESPINOZA Esther (2004) "La crónica de Carrillo y Valdelomar frente al proyecto modernizador" en Ínsula Barataria, 3; pp.58-65.

ESPINOZA, ESPINOZA Esther (2010): “Apuntes sobre Vallejo cronista” en Tesis 4; pp. 7-23. EGÁN, Linda. (2004) Cultura y crónica en el México contemporáneo. México: FCE.

GARCÍA CALDERÓN Ventura. (1986) Obras escogidas. Lima: Edubanco.

GONZÁLES, Aníbal. (1989) La crónica modernista hispanoamericana. Madrid, José Porrúa Turanzas,

LOAYZA, Luis. (1990) Sobre el 900. Lima: Mosca Azul Editores.

MARTÍNEZ BONATI, Félix. (2004) La agonía del pensamiento romántico. Santiago de Chile: Editorial Universitaria.

RAMOS, Julio. (1989) Desencuentros de la modernidad en América Latina. México: FCE.

ROTKER, Susana. (2005) La invención de la crónica. México: FCE.

ROTKER, Susana (1992) Fundación de una escritura. Las crónicas de José Martí. La Habana: Casa de las Américas.

SÁNCHEZ, Luis Alberto (1981) La literatura peruana. Tomo IV, Lima: Juan Mejía Baca.

VALENZUELA GARCÉS, Jorge (2011) "La experiencia narrativa de Ventura García Calderón: del decadentismo modernista a la cuentística del exotismo regionalista” En: Ricardo Silva Santisteban (ed.) Ventura García Calderón. Narrativa Completa. Lima: Pontificia Universidad Católica del Perú; pp.9-61. 